\title{
An Improved Film Thickness Model for Annular Flow Pressure Gradient Estimation in Vertical Gas Wells
}

Rahman MA*, Jacqueline Stevens, Jared Pardy and Danika Wheeler

Faculty of Engineering and Applied Sciences, Memorial University of Newfoundland, St. John's, NL, Canada

\begin{abstract}
The presence of liquids in natural gas wells increases the pressure loss within the well due to differences in density of the pressure head. In gas, well annular flow, liquid may be present in entrained droplets as well as in the liquid film. Several models have been proposed to predict liquid film thickness in pipes with vertical two-phase annular flow. Earlier models are based limited range of experimental data. The earlier models also require exhaustive iterative procedure to estimate liquid film thickness. On the other hand, the proposed modified film thickness model in this study was developed from a wide range of experimental data. The experimental data covers conditions of superficial liquid velocities ranging from 0.6 to $38.8 \mathrm{~cm} / \mathrm{s}$; superficial gas velocities ranging from 13.4 to $110.6 \mathrm{~m} / \mathrm{s}$; and diameters ranging from 12 to $51 \mathrm{~mm}$. The proposed model is compared with the available experimental data in the literature. Model predictions are in good agreement with the available experimental data set. The modified film thickness model helps accurate estimation of pressure gradient in vertical annular flow, which in turn is beneficial to the natural gas production industry as it further develops the understanding of production mechanics.
\end{abstract}

Keywords: Annular flow; Two-phase flow; Film thickness; Gas well

Nomenclature: $A$ : Area $\left(\mathrm{m}^{2}\right)$; $C f$ : Fanning Friction Factor (-); $D$ : Diameter (m); E: Fraction of Liquid Flow Entrained (-); Fr: Froude Number (-); g: Acceleration of Gravity; INTw: Wave Intermittency (-); Lwave: Size of Disturbance Waves; (m); LF: Fraction of Film With Linear Velocity Profile (-); $\left(\mathrm{kg} \mathrm{s}^{-1}\right)$ : Mass Flow Rate; $N \mu$ : Viscosity number (-); RD: Droplet Deposition Flux; Re: Reynolds Number (-); $U$ : Velocity $\left(\mathrm{m} \mathrm{s}^{-1}\right)$; $u$ : Friction velocity $\left(\mathrm{m} \mathrm{s}^{-1}\right)$; We: Weber Number (-); $x$ : Flow Quality (-); $y$ : Radial Coordinate (m); $\delta$ : Film Thickness (m); $\epsilon$ : Roughness (m); $\hat{?}$ Non-dimensional Roughness (-); $\mu$ : Viscosity (kg $\mathrm{m}-1 \mathrm{~s}-1) ; v$ : Kinematic Viscosity $\left(\mathrm{m}^{2} \mathrm{~s}^{-1}\right) ; \rho$ : Density $\left(\mathrm{kg} \mathrm{m}^{-3}\right) ; \sigma$ : Surface Tension $\left(\mathrm{N} \mathrm{m}^{-1}\right) ; \tau$ : Shear $(\mathrm{Pa})$.

Subscripts: Base: Base Film; Core: Core; Crit: Critical; Ent: Entrainment; Film: Film; G: Gas; I: Gas-Liquid Interface; L: Liquid; Max: Maximum (E.G., Entrainment); S: Superficial (E.G., Velocity); Rough: Roughness; Trans: Transitions Between Base Film And Waves; Wave: Waves.

\section{Introduction}

The presence of liquids in natural gas wells increases the pressure drop within the well due to differences in density of the pressure head. Two-phase flow is occurred when gas and liquid flow together in a pipe and this can take several forms of flow patterns. A common type of two-phase flow is annular flow, which is characterized by a slowmoving liquid film along the pipe walls and a fast-moving gas in the center of the pipe. In annular flow, liquid may be present in entrained droplets as well as in the aforementioned film. Understanding the pressure drop is paramount important for equipment sizing, operation, and production. To model the pressure, drop, the density of the twophase fluid must be determined. To determine this density, the amount of liquid, gas, and entrained liquid must be accurately computed. The density is a function of the void fraction between liquid and gas, which in turn is dependent on the film thickness and the entrained droplets within the gas.

The liquid film is characterized in two parts: a base film and a wavy disturbance layer, as shown in Figure 1. The amount of entrained liquid is dependent on the behaviour of this wavy disturbance layer and its

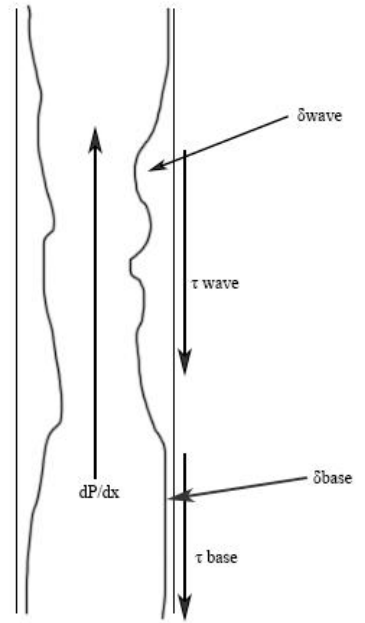

Figure 1: Two-phase annular flow components.

interaction with the gas component. In addition to density of the fluid, an understanding of the forces acting on the system is also important in understanding the pressure drop. Gravity, shear stresses, and drag forces all contribute to the velocity profiles, which in turn affect the characteristics of the liquid film and entrained droplets. The base film and wave film forces must be calculated separately in order to accurately determine the pressure drop of the system. A number of models have

"Corresponding author: Aziz Rahman, Adjunct Assistant Professor, Faculty of Engineering and Applied Science, Memorial University of Newfoundland, St John's, NL, Canada, A1B 3X5, Tel: (709) 737-8936; E-mail: marahman@mun.ca

Received January 24, 2017; Accepted February 25, 2017; Published February 28, 2017

Citation: Rahman MA, Stevens J, Pardy J, Wheeler D (2017) An Improved Film Thickness Model for Annular Flow Pressure Gradient Estimation in Vertical Gas Wells. J Pet Environ Biotechnol 7: 314. doi: 10.4172/2157-7463.1000314

Copyright: (c) 2017 Rahman MA, et al. This is an open-access article distributed under the terms of the Creative Commons Attribution License, which permits unrestricted use, distribution, and reproduction in any medium, provided the original author and source are credited. 
been proposed over the past 50 years to predict fluid behaviour and characteristics of two-phase annular flow. Many of the methods are applicable only to the experimental data set upon which they were based, while others are simply modifications of previous models. The following literature review discusses some of the significant proposed models and correlations related to film thickness, liquid entrained fraction, and pressure drop.

\section{Film thickness models}

Past attempts to quantify liquid base film thickness $(\delta)$ in a twophase system have resulted in significant progress in modeling natural gas transportation behaviour. There are numerous models to determine film thickness and entrainment. Schubring [1] completed a series of experiments using optical techniques, which measured base film thickness in annular two-phase flow. In these experiments horizontal and vertical conditions were examined and a correlation for each case was determined; the first being an empirical fit of the experimental data, and the second using a critical friction factor alongside an empirical fit. From the experiments, Schubring made a series of observations for the vertical case, such as: average base film thickness is inversely related to gas flow rate (superficial velocity) at constant liquid flow rate; for high gas flow rates, the dependence of average base film thickness on liquid flow rate vanishes; the average base film thickness is larger for larger tube diameters, however the dependence is less than linear; the film becomes more symmetric as the gas flow rate increases; vertical and horizontal average base film thicknesses have similar trends, however significant dependence on liquid flow rates remains at higher flow rates for the vertical geometry. The experiments included measuring superficial gas velocity against film thickness at fixed superficial liquid velocity values. This experiment included 3 horizontal cases using inside tube diameters of $8.8 \mathrm{~mm}, 15.1 \mathrm{~mm}$, and $26.3 \mathrm{~mm}$ and a vertical case having an inside diameter of $23.4 \mathrm{~mm}$.

Schubring were able to develop a model using an empirical correlation between film thickness roughness and tube length, gas and liquid density, and a Reynolds number. However, when incorporating the critical friction factor to develop the model an iterative process was developed. As the authors state, this process is most reliable when realistic values for film thickness and the base film velocity at the gas-liquid interface are used to calculate flow rates and the Reynolds number. This can be seen in the following set of equations.

$$
\frac{\delta}{\mathrm{D}}=4.7 \frac{1}{\mathrm{x}}\left(\frac{\mathrm{p}_{\mathrm{g}}}{\mathrm{p}_{1}}\right)^{\frac{1}{3}} \mathrm{R}_{\mathrm{G}}^{\frac{2}{3}}
$$

Where $\mathrm{R}_{\mathrm{G}}=\frac{\mathrm{G}}{\grave{\mathrm{i}}_{1}}, \mathrm{x}=\frac{\mathrm{m}_{\mathrm{g}}}{\mathrm{m}_{\mathrm{g}}+\mathrm{m}_{\mathrm{i}}}, \mathrm{G}=\frac{\mathrm{m}_{\mathrm{g}}+\mathrm{m}_{\mathrm{i}}}{\mathrm{A}}$

Based on the findings, Schubring concluded that base film thickness is most strongly connected to gas flow and the effect of liquid flow rate is more significant at lower gas flows and in the vertical geometry. They also noted that uncertainties varied with the film thickness, tube thickness, and surface roughness. Typical base film thickness uncertainties for the horizontal tube were around $2 \%$ for high gas flows and 5\% for low gas flows. Uncertainties were higher in the vertical tube (approximately 15\%) due to the decreased wall thickness. Expanding upon their past research, Schubring [2] conducted another series of experiments using planar laser-induced fluorescence (PLIF) in a vertical tube with an annular flow regime of an air-water mixture in order to quantify the liquid film thickness. By introducing fluorescent dye into the water, the thin film layer could be measured after a series of imaging processing. By detecting the presence of the dye at the surface of the film the thickness could then be determined. This experimental method proved advantageous over past methods as it allowed for a visual of the film after processing, which showed the differences between the base film and the waves that are observed during annular flow. The data obtained was applied to the Wallis [3] singlezone interfacial shear correlation, the Owen and Hewitt [4] correlation, and finally, the twozone model by Hurlburt. For the Wallis [3] correlation, results at low liquid flow rates are consistent with the experimental data. However, for high liquid flow rates the Wallis model is not suitable for annular flow film thickness predictions due to its inconsistencies with the experimental data. Typically, the Owen and Hewitt [4] correlation, essentially a more complex version of the Wallis correlation, uses the entrainment fraction as an input to output film height and pressure loss, however, by using film height as an input, the entrainment fraction and pressure loss are found. It was observed that the Owen and Hewitt [4] correlation performed similarly to the Wallis [3] correlation in that for low liquid flow rates the predictions for pressure loss are consistent with experimental data, however, at high liquid flow rates the model diverges. The analysis noted that the Owen and Hewitt [4] model was no better than other correlations.

Finally, a two-zone model presented originally by Hurlburt [5] was applied to the experimental data. This model uses a roughnessmodified log law to model interfacial shear and was found to be inferior to the inaccurate aforementioned models. More specifically, the effect of liquid flow on interfacial shear is underestimated while the effect of gas flow is overestimated. Furthermore, for this model the entrainment fraction is not a strong function of gas flow, which is not consistent with the experimental data presented. In its entirety, this model provided an acceptable prediction, particularly at a low superficial liquid velocity, however it is bested by the Wallis [3] correlation, and the Owen and Hewitt [4] correlation.

From the analysis, Schubring [6] concluded that average film thickness is found to be an increasing function of liquid flow and a decreasing function of gas flow. For the present experimental data sets, the models discussed here all under-predict the importance of increasing liquid flow on pressure loss and interfacial shear. Finally, since high liquid flow rates in annular flow induce disturbance wave and entrainment activity, further modeling in these areas is needed. This paper proposes a new film thickness model that has been developed by correlating to a wide range of experimental data. This model is based on Reynolds, Weber, and Froude dimensionless numbers and requires only diameter, fluid properties, and flow rates as inputs.

\section{Entrained liquid fraction models}

In addition to accurate predictions of film thickness, determining the fraction of entrained liquid in the gas core is critical in correctly calculating core density and pressure drop. A number of experimental data sets and models have been proposed to attempt to estimate entrainment. Most models however are limited to the experimental data sets from which they were correlated. Entrainment is the fraction of liquid entrained as droplets in the gas core - it has a range between 0 and 1 , with 0 being perfect gas/ liquid separation and 1 being the transition from annular to dispersed mist flow. One of the earliest models for predicting entrained liquid fraction is the work of Steen and Wallis [6]. This model was developed graphically and is highly limited to low liquid and gas flow rates. A number of pressure drop models used this model to estimate entrainment due to its simplicity. Recent work on studying entrainment and associated models has been done by Cioncolini and Thome $[7,8]$ who compared a number of proposed entrainment models against a broad range of experimental data and 
proposed another model that incorporates a refined Weber number. The data set includes 8 different gas-liquid combinations and over 19 different tube diameters. Inlet effects are not considered in this study, as the experimental setups have been designed to remove any dependence on the inlet conditions.

Cioncolini and Thome [8] observed that the best predictions of entrainment for the entire data set are given by the Sawant [9] correlation, followed by Ishii and Mishima and Pan and Hanratty $[10,11]$. If the entrained liquid fraction is above 0.5 , the best predictions are given by Oliemans followed by Sawant $[9,12]$. The correlation presented by Oliemans requires an elaborate equation for entrainment:

$$
\frac{\mathrm{e}}{1-\mathrm{e}}=10^{\mathrm{b}_{0}} \rho_{1}^{\mathrm{b}_{1}} \rho_{\mathrm{g}}^{\mathrm{b}_{2}} \mu_{1}^{\mathrm{b}_{3}} \mu_{\mathrm{g}}^{\mathrm{b}_{4}} \sigma^{\mathrm{b}_{5}} \mathrm{~d}^{\mathrm{b}_{6}} \mathrm{~J}_{1}^{\mathrm{b}_{7}} \mathrm{~J}^{\mathrm{b}_{8}} \mathrm{~g}^{\mathrm{b}_{9}}
$$

In this equation, entrainment is a function of many different parameters. The exponents b0 - b9 are dependent on the liquid film Reynolds number, and are given in a tabular form in the literature. The definition of the Reynolds number for this model depends on the fraction of entrained liquid. This results in a tedious iterative procedure to calculate entrainment. This model does not include density and viscosity of the droplet laden core but uses density and viscosity of the gas and liquid separately and therefore fails to properly capture the effect of the entrainment process on the core flow properties Cioncolini and Thome [8].

Ishii and Mishima [9] developed a correlation to predict the liquid entrainment fraction in the quasi-equilibrium annular flow region. The equilibrium entrainment fraction is when the rate of droplet entrainment equals the rate of droplet deposition. Their correlation is non-dimensional, explicit and was developed based on low pressure air-water data. The correlation was developed using an entrainment fraction of 1.0 as the upper boundary limit. More recent experimental data has shown that it is not possible to entrain all of the liquid from the liquid film even at very high gas velocities therefore their model fails to predict the observed trends at higher gas velocities. Sawant [9] proposed a correlation that uses dimensionless numbers for ease of use. Up until the introduction of this model, other correlations have proved to only be accurate for low flow, low pressure conditions. The model of Sawant [9] was developed to be able to accurately predict entrainment behaviour at high flow and high pressure conditions.

$$
\frac{\mathrm{E}}{\mathrm{E}_{\mathrm{m}}}=\tan \mathrm{h}\left[2.31 \times 10^{-4} \mathrm{R}_{l}^{-0.3}\left(\mathrm{~W}-\mathrm{W}_{\mathrm{c}}\right)^{1.2}\right]
$$

The calculation requires the prediction of maximum entrained liquid fraction, Emax:

$$
\mathrm{E}_{\mathrm{m}}=1-\frac{13 \mathrm{~N}_{\mathrm{i}}^{-0.5}+0.3\left(\mathrm{R}_{l}-13 \mathrm{~N}_{\mathrm{i}}^{-0.5}\right)^{0.9}}{\mathrm{R}_{l}}
$$

Sawant [9] stated that the prediction of the maximum entrainment parameter requires further refinement and is therefore the constraint to their model. Cioncolini and Thome [8] determined that the core flow Weber number is the dominant dimensionless group in predicting the entrained liquid fraction. They developed a correlation based on this parameter:

$$
\begin{aligned}
& \mathrm{E}=\left(1+13.18 \mathrm{~W}_{\mathrm{c}}^{-0.6}\right)^{-1.7} \\
& W_{e_{\text {core }}} \text { is the core flow Weber number, given as: } \\
& \mathrm{W}_{\mathrm{c}}=\frac{\rho \mathrm{cV}_{\mathrm{c}}^{2} \mathrm{~d}_{\mathrm{c}}}{\mathrm{o}}
\end{aligned}
$$

They note, however, that accurate prediction of the core Weber number requires an accurate prediction of the average liquid film thickness, which results in an iterative calculation procedure. Their recommendations for further work include more experimental investigation concentrated on obtaining accurate data on the entrained liquid fraction. They recommend focusing on annular flows with high entrained liquid fractions as this appears to be where most models fail to accurately predict experimental data. This paper incorporates the Sawant [9] entrainment model into a modified pressure drop model. The choice of this model is validated by comparing its results with experimental data and by comparing it with results from other widely used entrainment models proposed by Steen and Wallis, Ishii and Mishima [7,10].

\section{Pressure-drop models}

Theoretical analysis of vertical flow began in the 1930s however it was not until the 1950s that correlations between all the various factors involved began to be documented. Gilbert [13] proposed complex empirical correlations for pressure drop in gas-liquid vertical flow but his method is based on limited production rates and conditions. Poettman and Carpenter [14] used an energy-balance method, a simplified Reynolds number and a limited amount of low flow rate measured field data as the basis of their theory. This method treats the system as a single-phase, which fails to take into account all the components of the energy balance and does not consider liquid/gas void fraction in the calculation of the overall mixture density. The discrepancies between measured data and these early correlations justified the need for largescale laboratory experimental data to be used to find more suitable models and correlations to understand two-phase annular vertical flow. Duns and Ros [15] proposed the use of the pressure balance equation rather than an energy balance equation and also included the liquid holdup/void fraction in the density calculation. The pressure balance equation includes static, friction, and acceleration gradients which allows for distinguishing between the vertical two-phase flow patterns. Ultimately, this introduction to differentiating between flow patterns led to the refinement of modeling vertical two-phase annular flow. All the early work was done in short-tube laboratory apparatuses making it difficult to apply to actual field conditions where well tubing lengths are much longer. Hagedorn and Brown [16] ran experiments in longer tubes and used the data to develop more generalized correlations for pressure drop in vertical two-phase flow. Orkiszewski [16] developed pressure drop prediction correlations that were based on identifying the specific two-phase flow pattern. His method roved to be complex and is not fully tested for annular flow patterns. The models presented in the early work from the 1960s are valid only for the conditions under which the experimental data was taken. Aziz and Ansari $[17,18]$ developed models that can be applied to a wider range of operating conditions. Their correlations elaborated on the early work and proposed models that predict annular flow behaviour using physical characteristics. Up until this date, all the early models were characterized by the rigorous steps involved to describe the physical nature of the annular flow which relied on determination of liquid film thickness, liquid entrainment, and interfacial shear stress. Hasan and Kabir [19] present a simplified model that assumes the liquid-film thickness is too small to have any significant contribution to computing accurate pressure drops. This method simplifies the mechanical energy balance by assuming the liquid film thickness is zero such that all of the liquid is moving through the core at the same velocity as the liquid. The core velocity equals the sum of the superficial liquid velocity and the superficial gas velocity. The Chen [20] correlation is used to determine the friction factor used in the pressure drop equation. The roughness 
value used in the correlation is that for the pipe wall, ignoring the wavyliquid film. When compared to other models, this approach proved to match experimental data just as well. A recent model proposed by Schubring and Shedd [2] ignores the simplified approach and presents a model that is predominantly based on mass balance principles and by dividing the model into a base film zone and a wave zone. The model does not assume an average liquid film thickness but requires a base film thickness input and then assumes an average wave film thickness of two times that of the base film. Interfacial shear of the base film, wave roughness, and wave transitions are all estimated. While this method requires a number of parameters to be calculated, the inputs are only flow rate, fluid properties, and geometry. A time-averaged pressure gradient can be calculated based on the intermittency of the liquid film waves. The proposed modified model is compared against the Schubring [2], Ansari [18], and Hasan and Kabir models [19].

\section{Theory}

\section{Liquid entrainment model}

Using experimental data in the literature Sawant [9] proposed an entrainment model as follows:

$$
\begin{aligned}
& \mathrm{E}=\mathrm{E}_{\mathrm{m}} \times \tan \mathrm{h}\left[2.31 \times 10^{-4} \mathrm{R}_{l}^{-0.3}\left(\mathrm{~W}_{e}-\mathrm{W}_{\mathrm{c}}\right)^{1.2}\right] \\
& \mathrm{E}_{\mathrm{m}}=1-\frac{13 \mathrm{~N}_{\mu}^{-0.5}+0.3\left(\mathrm{R}_{l}-13 \mathrm{~N}_{\mu}^{-0.5}\right)^{0.9}}{\mathrm{R}_{l}}
\end{aligned}
$$

Superficial liquid Reynolds number Rel and viscosity number $N \mu$ is defined as follows:

$$
\begin{aligned}
& R_{l}=\frac{\rho_{l} U_{s} D}{\mu_{l}} \\
& N_{\mu}=\mu_{l}\left(\rho_{l} \sigma \sqrt{\frac{\sigma}{g\left(\rho_{l}-\rho_{g}\right)}}\right)^{-0.5}
\end{aligned}
$$

Weber number and critical Weber number can be calculated as follows:

$$
\begin{aligned}
& W=\frac{\rho_{g} U_{s}^{2}}{\sigma}\left(\frac{\rho_{l}-\rho_{g}}{\rho_{g}}\right)^{0.2} \\
& W_{c}=\frac{\rho_{g} U_{s}^{2} D}{\sigma}\left(\frac{\rho_{l}-\rho_{g}}{\rho_{g}}\right)^{0.2}
\end{aligned}
$$

Critical Superficial Gas Velocity $(R e \leq 1635)$

$$
U_{s}=\frac{11.78 R l^{-0.3} N_{\mu}^{0.8}}{\frac{\mu_{l}}{\sigma} \sqrt{\frac{\rho_{g}}{\rho_{l}}}}
$$

\section{New film thickness model}

Based on available experimental data, a new film thickness model was developed from a range of experimental data sets. These data sets come from the works of Schubring [1,21-23], Bai and Newell, Alamu, Azzopardi, Paz, Shoham and Butterwoth [24-27]. The experimental data sets cover conditions of superficial liquid velocities ranging from
0.6 to $38.8 \mathrm{~cm} / \mathrm{s}$; superficial gas velocities ranging from 13.4 to 110.6 $\mathrm{m} / \mathrm{s}$; and diameters ranging from 12 to $51 \mathrm{~mm}$. The new film thickness model is based on Reynolds, Weber, and Froude dimensionless numbers and thus requires only diameter, fluid properties, and flow rates as inputs.

$$
\delta_{\bmod }=1.93 \times 10^{-3}(\mathrm{Re})^{-0.246}(W e)^{-0.161}\left(m_{L} / m_{G}\right)^{0.546}(F r)^{0.15}
$$

Where, $R e=\rho g \mathrm{Usg} \mathrm{D} / \mu \mathrm{l}, W e=\rho \mathrm{gUsg}{ }^{2} \mathrm{D} / \sigma, \mathrm{Fr}=\mathrm{Usl}^{2} / \mathrm{gD}$

Previously proposed models rely on correlated methods and empirical data from experiments that cover a narrow range of data to determine base film thickness as well as wave thickness. The new film thickness model has been developed from past experimental results, which collectively cover a broad range of diameters, fluid properties, and flow rates. The new model therefore provides a better model than those previously proposed.

\section{Pressure drop model}

The newly proposed film thickness model and Sawant [9] proposed entrainment model is used to calculate the pressure loss in an annular flow using Schubring and Shedd model as follows:

$$
\frac{d}{d}=\left(1-\pi_{w}\right) \frac{d}{d_{b}}+\pi_{w} \frac{d}{d_{w}}
$$

\section{Results and Discussion}

\section{Validation of new model with experimental data}

Results from the new model were compared with results presented by Schubring [1,22], Alamu and Azzopardi and Butterwoth [26,27]. Each author has developed their respective film thickness models based on a series of experiments that use diameters ranging from $19 \mathrm{~mm}$ to $31.75 \mathrm{~mm}$. As such it is not acceptable to directly compare the values for experimental film thickness with the values calculated by the new model. In order to circumvent the inability to directly compare these values, both experimental film thickness and modeled film thickness have been normalized with their respective diameters and presented in the form of $\delta / D$. The Figure 2 represents a comparison between normalized values of experimental film thickness values and film thickness values calculated by the new model.

For complete agreement between experimental data and model results, the values from Figure 3 should lay on the line $y=x$, however it can be seen that the majority of the points in this figure lie within

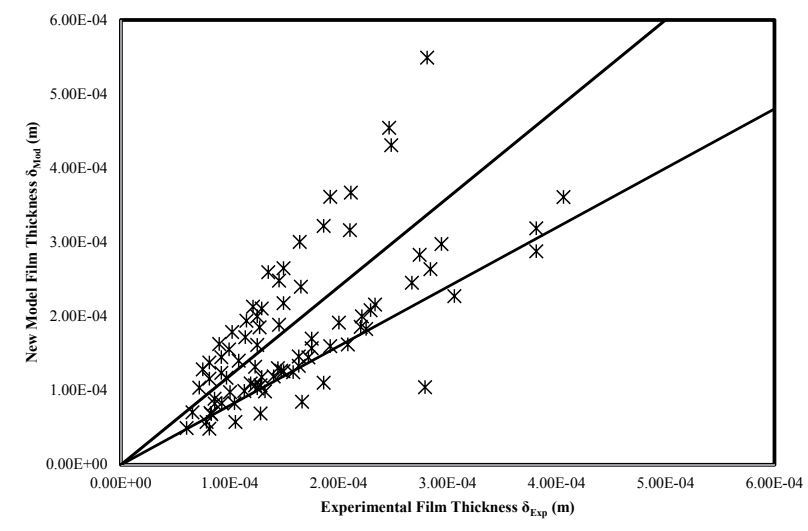

Figure 2: Comparison of new film thickness models with experimental data. 
Citation: Rahman MA, Stevens J, Pardy J, Wheeler D (2017) An Improved Film Thickness Model for Annular Flow Pressure Gradient Estimation in Vertical Gas Wells. J Pet Environ Biotechnol 7: 314. doi: 10.4172/2157-7463.1000314

Page 5 of 8

the $+/-20 \%$ tolerances. Therefore, the comparison between the new film thickness model and experimental film thickness data reveals that the model is indeed an appropriate approximation of experimental film thickness values for wider range of experimental data.

Further analysis of the new model and past models developed by Elvis, and Alamu with experimental measurements of film thickness reveal that the new model does indeed provide better predictions [26]. Figure 4 shows the comparison of film thickness models with experimental data and other models. The comparison of film thickness models with experimental data and other models clearly shows that while the values for the new model mostly reside within the acceptable area of $+/-20 \%$ of experimental data, values from Elvis and Alamu [22] reside outside this area. It can be noted that the models presented by Elvis and by Ansari [19] show a tendency to over predict film thickness, while the model presented by Elamu, greatly under predicts experimental film thickness values.

The inability to predict experimental results from models presented

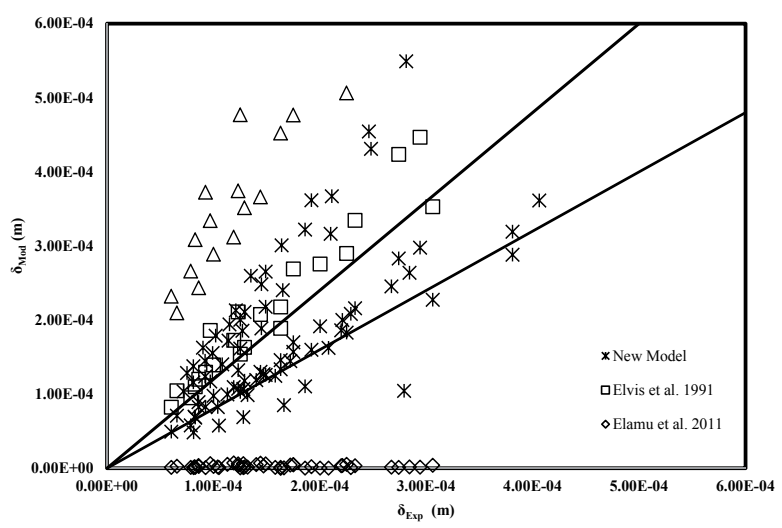

Figure 3: Comparison of film thickness models with experimental data.

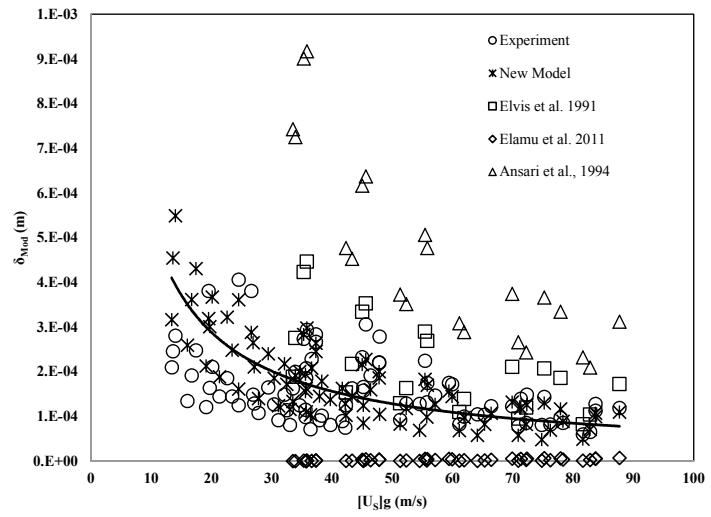

Figure 4: Comparison of film thickness models with superficial gas velocity.

\begin{tabular}{|c|c|c|c|c|c|c|}
\hline & $\begin{array}{l}\text { Diameter } \\
(\mathrm{mm})\end{array}$ & $\mathbf{U}_{\mathrm{sg}}$ & $U_{s l}$ & $\begin{array}{c}\text { Gas } \\
\text { Density } \\
\left(\mathrm{kg} / \mathrm{m}^{3}\right)\end{array}$ & $\begin{array}{l}\text { Liquid } \\
\text { Density } \\
\left(\mathrm{kg} / \mathrm{m}^{3}\right)\end{array}$ & $\begin{array}{c}\text { Inlet } \\
\text { Pressure } \\
(\mathrm{kPa})\end{array}$ \\
\hline \multirow{2}{*}{$\begin{array}{l}\text { Sawant et } \\
\text { al. (2008) }\end{array}$} & \multirow{2}{*}{9.4} & $\begin{array}{c}21.1- \\
99.4\end{array}$ & \multirow{2}{*}{$\begin{array}{c}0.05- \\
0.53\end{array}$} & 2 & \multirow{2}{*}{1000} & 120 \\
\hline & & $\begin{array}{c}15.7- \\
97.8\end{array}$ & & 4 & & 400 \\
\hline $\begin{array}{l}\text { Owen et } \\
\text { al. }(1989)\end{array}$ & 31.8 & $\begin{array}{c}97.4- \\
470\end{array}$ & $\begin{array}{c}0.05- \\
0.11\end{array}$ & 2 & 1000 & 100 \\
\hline
\end{tabular}

Table 1: Liquid entrainment fraction experimental data conditions.

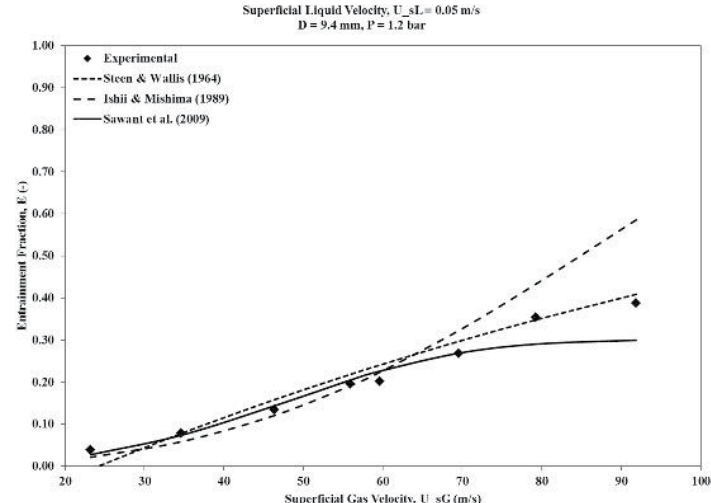

Figure 5: Entrainment model results vs. Sawant [1] data, UsL $=0.05 \mathrm{~m} / \mathrm{s}, \mathrm{P}=$ 1.2 bar.

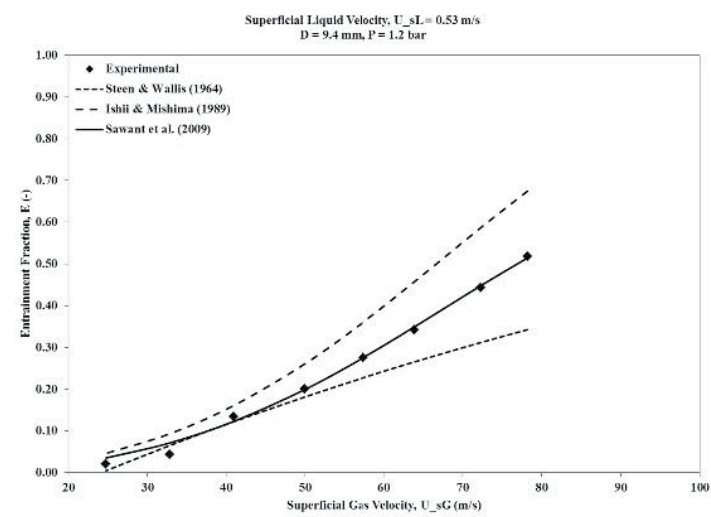

Figure 6: Entrainment model results vs. Sawant [1] data, UsL $=0.53 \mathrm{~m} / \mathrm{s}, \mathrm{P}=$ 1.2 bar.

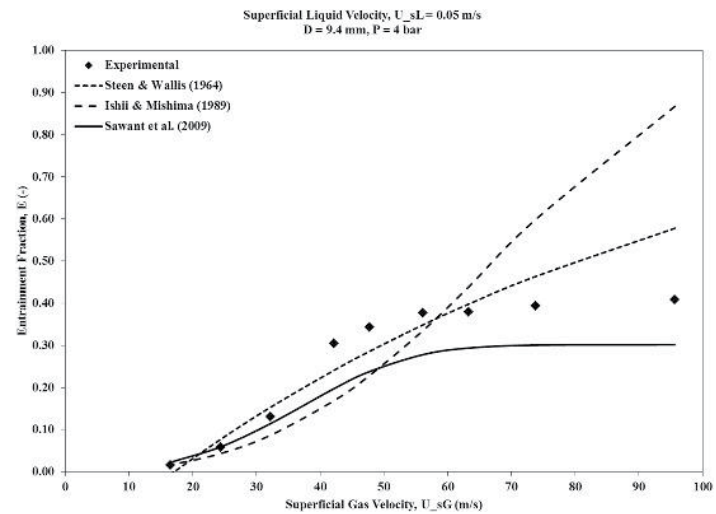

Figure 7: Entrainment model results vs. Sawant [1] Data, UsL $=0.05 \mathrm{~m} / \mathrm{s}, \mathrm{P}$ $=4$ bar

by Elvis and Elamu can also be observed in Figure 4 by the interaction between film thickness and varying superficial gas velocity. The new model remains the more accurate model, as it does not appear to deviate from the film thickness trends captured by the experimental data therefore validating the use of this new model developed in this study.

\section{Entrainment model selection}

To simplify the model presented by Schubring and Shedd [2], 
Citation: Rahman MA, Stevens J, Pardy J, Wheeler D (2017) An Improved Film Thickness Model for Annular Flow Pressure Gradient Estimation in Vertical Gas Wells. J Pet Environ Biotechnol 7: 314. doi: 10.4172/2157-7463.1000314

a model to estimate liquid entrainment fraction was chosen from existing models. Steen, Wallis, Ishii, Mishima and Sawant $[7,9,10]$ were compared against experimental data to determine a suitable choice. Experimental data was extracted from literature from Sawant and Owen [4]. Table 1 presents the conditions under which the experimental data sets were generated.

Validation with Sawant experimental data [1]: Figures 5-8 compare the Sawant [9] entrainment model with the Steen and Walls and Ishii and Mishima [7,10] models against the Sawant [12] experimental data. The graphs show the trend of entrainment fraction with increasing superficial gas velocity. While each model's predictions agree well with experimental data at low pressure and low liquid flow rates, only the Sawant [12] model predicts the trends at higher liquid flow rates and higher pressures. Ishii and Mishima [9] over predict at higher

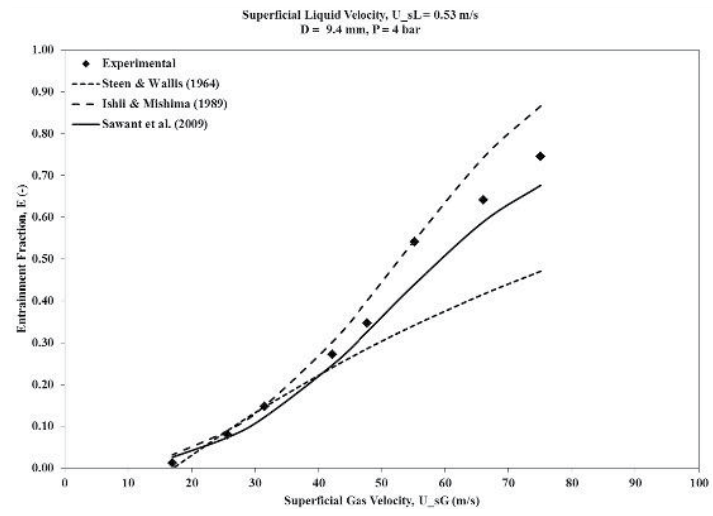

Figure 8: Entrainment model results vs. Sawant [1] Data, UsL $=0.05 \mathrm{~m} / \mathrm{s}, \mathrm{P}$ $=4$ bar.

\begin{tabular}{|c|c|c|c|c|}
\hline \multirow{2}{*}{} & \multicolumn{3}{|c|}{ Average \% Difference = (Model - Exp)/Exp*100 } \\
\cline { 2 - 5 } & $\begin{array}{c}\text { UsI = } \\
\mathbf{0 . 0 5 m} / \mathbf{s}\end{array}$ & UsI = $\mathbf{0 . 5 3 m / s}$ & UsI = 0.05m/s & UsI = 0.53m/s \\
\cline { 2 - 5 } & $\mathrm{P}=1.2 \mathrm{bar}$ & $\mathrm{P}=1.2 \mathrm{bar}$ & $\mathrm{P}=4 \mathrm{bar}$ & $\mathrm{P}=4 \mathrm{bar}$ \\
\hline $\begin{array}{c}\text { Sawant et al. } \\
\text { (2009) }\end{array}$ & $-6 \%$ & $16 \%$ & $-15 \%$ & $5 \%$ \\
\hline $\begin{array}{c}\text { Ishii and Mishima } \\
\text { (1989) }\end{array}$ & $3 \%$ & $52 \%$ & $3 \%$ & $29 \%$ \\
\hline $\begin{array}{c}\text { Steen and Wallis } \\
\text { (1964) }\end{array}$ & $-7 \%$ & $-19 \%$ & $-7 \%$ & $-29 \%$ \\
\hline
\end{tabular}

Table 2: \% Difference of entrainment model results with Sawant et al. (2008) experimental data.

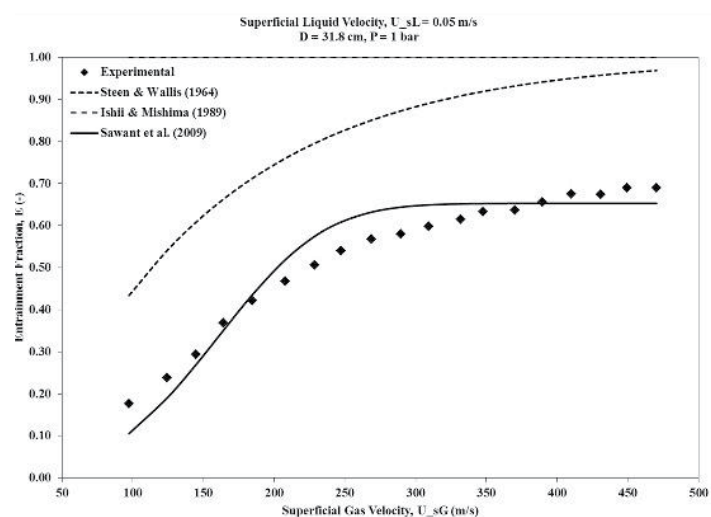

Figure 9: Entrainment model results vs. Owen [4] Data, UsL $=0.05 \mathrm{~m} / \mathrm{s}, \mathrm{P}=$ 1 bar.

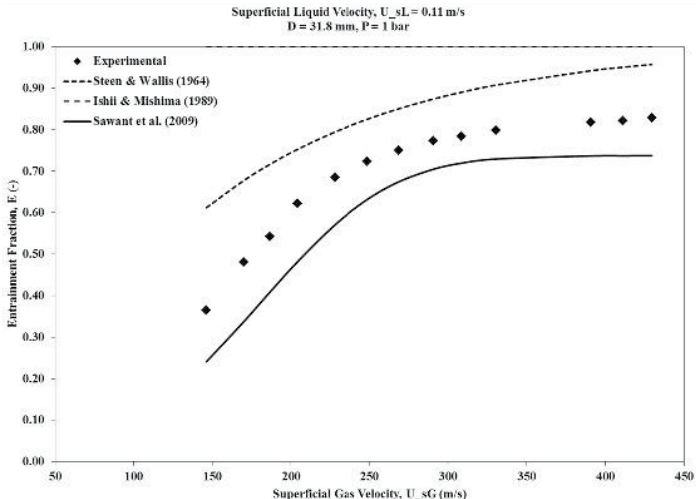

Figure 10: Entrainment model results vs. Owen [4] Data, UsL $=0.11 \mathrm{~m} / \mathrm{s}, \mathrm{P}=$ 1 bar.

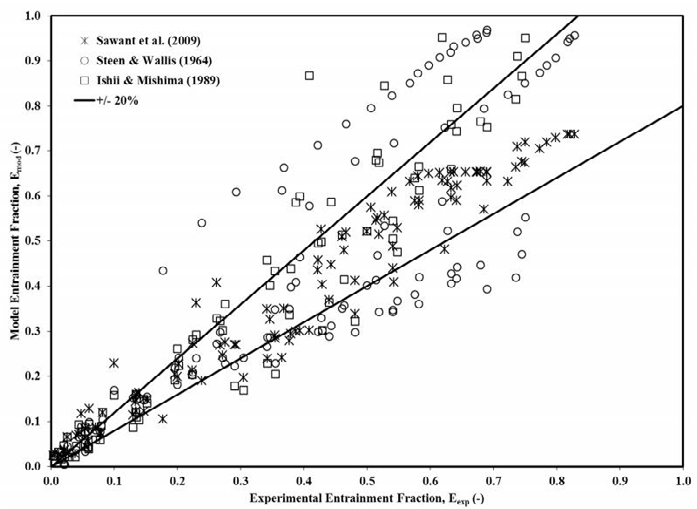

Figure 11: Comparison of entrainment model results with experimental data.

\begin{tabular}{|c|c|c|c|c|c|c|}
\hline & $\begin{array}{c}\text { Diameter } \\
(\mathbf{m m})\end{array}$ & $\begin{array}{c}\text { Usg } \\
(\mathbf{m} / \mathbf{s})\end{array}$ & $\begin{array}{c}\text { Usl } \\
\mathbf{( m / s )}\end{array}$ & $\begin{array}{c}\text { Gas } \\
\text { Density } \\
\mathbf{( k g / m 3 )}\end{array}$ & $\begin{array}{c}\text { Liquid } \\
\text { Density } \\
\mathbf{( k g / m 3 )}\end{array}$ & $\begin{array}{c}\text { Inlet } \\
\text { Pressure } \\
\mathbf{( k P a )}\end{array}$ \\
\hline $\begin{array}{c}\text { Schubring } \\
\text { et al. } \\
(2010 \mathrm{c})\end{array}$ & 23.4 & $34-76$ & $\begin{array}{c}0.04- \\
0.35\end{array}$ & 1.2 & 1000 & 100 \\
\hline
\end{tabular}

Table 3: Pressure drop experimental data conditions.

gas flow rates because their model was developed using an entrainment fraction of 1.0 as the upper boundary limit. In reality, as presented by the experimental data, the entrainment fraction approaches the limit much lower than one at high gas velocities. Table 2 summarizes the average $\%$ difference of each model with experimental data.

Validation with Owen experimental data [4]: Figures 9 and 10 compare the Sawant [9], Steen and Walls [6], and Ishii and Mishima [9] entrainment models against the Owen [4] experimental data. Again, due to the assumption inherent in the Ishii and Mishima [9] model that all the liquid can be entrained at high gas flow rates, their model fails to predict experimental data for this set. Their model predicts entrainment of $\sim 1.0$. Steen and Wallis [6] predicts the overall trend but at the low liquid flow rate the predictions are $\sim 63 \%$ greater than experimental. Similarly, at the high liquid flow rate the predictions are $\sim 22 \%$ greater than experimental. The Sawant [9] model matches the observed trends in close agreement, within $+/-20 \%$ for both data sets. At the low liquid flow rate the predictions are on average $\sim 0.4 \%$ less than experimental. Similarly, at the high liquid flow rate the predictions are $\sim 16 \%$ less than experimental. For both experimental data sets of Sawant and Owen, 
the Sawant $[4,6,9]$ model agrees within $+/-20 \%$. Figure 11 summarizes the comparison of all three models with experimental data. Steen and Wallis and Ishii and Mishima $[7,10]$ both fail to agree with experimental data within suitable limits and fail to predict observed trends at high gas flow rates and higher pressures. Ability to predict entrainment at these conditions is critical for modelling annular flow in natural gas wells as high gas flow rates and high pressures are typical operating conditions. Sawant [9] is a suitable choice of entrainment model due to its simplicity and validation with experimental data.

\section{Validation of modified pressure drop model}

The modified pressure drop model presented in the previous section was compared against experimental data and models of Ansari and Hasan and Kabir $[19,20]$ to validate that the model, though simplified, agrees with Schubring and Shedd's [2] results and predicts better than the other models studied. The modified model is a simplification of the Schubring and Shedd [2] mass balance / two zone approach. Ansari [19] is a semi-mechanistic approach that uses Steen and Wallis [6] to estimate entrainment and uses Wallis [3] to estimate the core friction factor which requires determining a wall friction factor and a superficial liquid friction factor. Hasan and Kabir [20] is a homogeneous model that is less rigorous than both Schubring and Shedd and Ansari $[2,19]$. It assumes that the liquid film may be ignored and that all the liquid therefore moves through the core with the gas phase at equal velocities. The model uses the correlations proposed by Chen to compute the two-phase friction factor [21]. Experimental data was extracted from

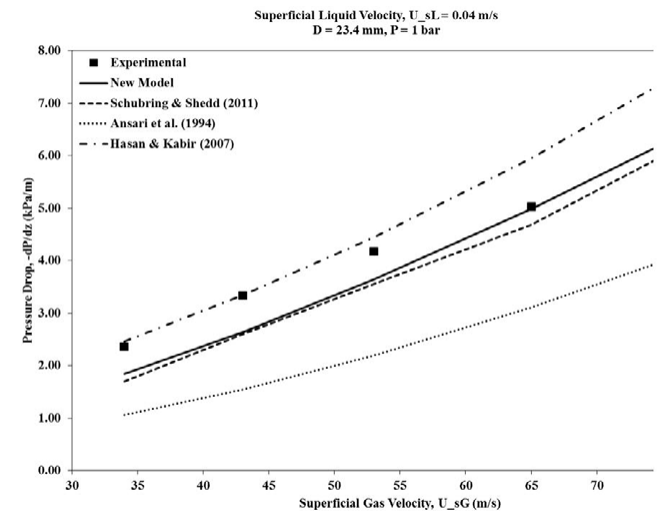

Figure 12: Pressure drop model results vs. Schubring [22] Data, UsL $=0.04$ $\mathrm{m} / \mathrm{s}, \mathrm{P}=1$ bar.

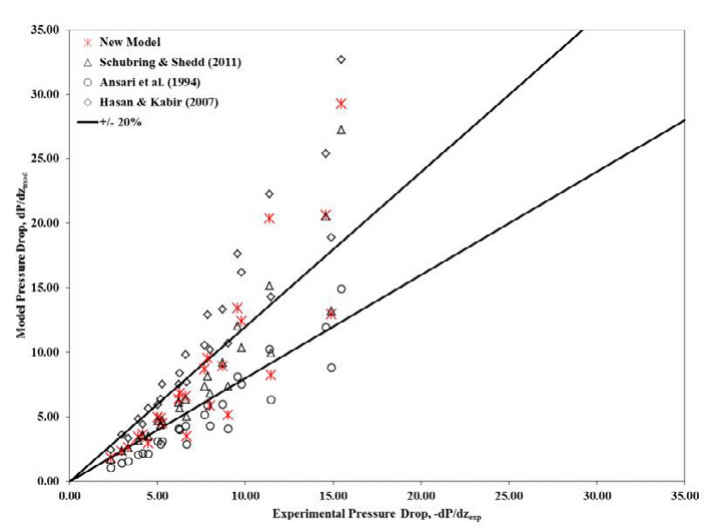

Figure 13: Comparison of pressure drop models with experimental data. literature from Schubring [23]. Table 3 presents the conditions under which the experimental data sets were generated.

\section{Validation with Schubring experimental data}

Figure 12 compares the modified pressure drop model with the Schubring and Shedd [2], Ansari [19], and Hasan and Kabir [20] models against the experimental data of Schubring [23]. All models capture the trend that with increased flow rates, pressure drop will also increase. Hasan and Kabir [20] consistently over-predict while Ansari [19] under-predict. The modified model proves to agree with the predictions of the Schubring and Shedd [2] model. As presented in Figure 13 at high gas flow rates $(65$ and $76 \mathrm{~m} / \mathrm{s}$ ) and high liquid flow rate $(0.35 \mathrm{~m} / \mathrm{s})$, experimental data shows that pressure drop does not continue to increase. All models fail to capture this trend. Some authors have seen that at these high rates the entrained droplets cluster together within the core and exhibit a wispy-annular type flow regime. The twozone model, and therefore the modified model, are not able to predict this behaviour accurately. The modified model, while a simplified version of Schubring and Shedd [2], still agrees with experimental data and agrees with Schubring and Shedd's [2] results.

\section{Conclusion}

A modified two-phase vertical annular flow pressure drop model has been proposed based on simplification of Schubring and Shedd's [2] model. A new film thickness model has been proposed and incorporated into the model for simplification purposes. The new film thickness model is a simply model that requires only flow rates and fluid properties and is based on dimensionless terms. Further simplification was achieved by incorporating the entrainment model of Sawant [9] and by simplifying the characteristic gas velocity calculation to eliminate an integral term. The results of the simplified modified model agree well with experimental data and agree with Schubring and Shedd's [2] results and predict better than other earlier pressure drop models of Ansari, Hasan and Kabir [19,20].

The conclusions drawn from this study are as follows:

a) A new model was developed to calculate the film thickness for annular flow.

b) Hydrodynamic force balance was applied to develop the new model.

c) The newly developed model can reliably predict experimental data compared to other models.

d) The new model will help to reliably predict gas well pressure gradient for a wide range of operating conditions.

\section{Acknowledgement}

The author would like to acknowledge Mr. Jared Pardy, Ms. Danika Wheeler and Ms. Jacqueline Stevens for a contribution to this paper through their project work. The author also would like to acknowledge Mr. Xiao Xiong for editorial contribution.

\section{References}

1. Schubring D, Ashwood A, Hurlburt E, Shedd T (2008) Optical measurement of base film thickness in annular two-phase flow. FEDSM2008. Jacksonville, Florida: ASME Fluids Engineering Conference.

2. Schubring D, Shedd T (2011) A model for pressure loss, film thickness, and entrained fraction for gas-liquid annular flow. International Journal of Heat and Fluid Flow.

3. Wallis G (1969) One-dimensional two-phase flow. New York: McGraw-Hill.

4. Owen D, Hewitt G, Bott T (1985) Equilibrium annular flows at high mass fluxes; data and interpretation. PCH Physiochem. Hydrodynamics. 
Citation: Rahman MA, Stevens J, Pardy J, Wheeler D (2017) An Improved Film Thickness Model for Annular Flow Pressure Gradient Estimation in Vertical Gas Wells. J Pet Environ Biotechnol 7: 314. doi: 10.4172/2157-7463.1000314

5. Schubring D, Ashwood A, Shedd T, Hurlburt E (2010) Planar laser-induced fluorescence (PLIF) measurements of liquid film thickness in annular flow. International Journal of Multiphase flow 36: 815-835.

6. Steen D, Wallis G (1964) AEC report, No. NYO-31142-2.

7. Cioncolini A, Thome $\mathrm{J}$ (2010) Prediction of the entrained liquid fraction in vertical annular gas-liquid two-phase flow. International Journal of Multiphase Flow 36: 293-302.

8. Sawant $P$, Ishii M, Mori M (2009) Prediction of amount of entrained droplets in vertical annular two-phase flow. International Journal of Heat and Fluid Flow 30: $715-728$

9. Ishii M, Mishima K (1989) Droplet entrainment correlation in annular two-phase flow. International Journal of Heat and Mass Transfer. p: 1835-1846.

10. Pan L, Hanratty T (2002) Correlation of entrainment for annular flow in vertical pipes. . Int J Multiph Flow.

11. Sawant $P$, Ishii M, Mori M (2008) Droplet entrainment correlation in vertical upward co-current annular two-phase flow. Nuclear Engineering and Design 238: $1342-1352$

12. Gilbert W (1954) Flowing and gaslift well performance. Drill. and Prod. Pract, API, 126.

13. Poettman F, Carpenter $P$ (1961) Multiphase flow of gas, oil and water through vertical flow strings. Drill. and Prod. Pract, API, 257.23

14. Duns H, Ros N (1963) Vertical flow of gas and liquid mixtures in wells Netherlands: Section II-Paper 22-PO6.

15. Hagedorn A, Brown K (1965) Experimental study of pressure gradients occuring during continuous two-phase flow in small-diameter vertical conduits. J Pet Technol 17: 475-484.

16. Orkiszewski J (1967) Predicting two-phase pressure drops in vertical pipe. J Pet Technol 19: 329-338.
17. Aziz K, Grovier G, Fogarasi M (1972) Pressure drop in wells producing oil and gas. J Can Petrol Technol 11: 38-48.

18. Ansari A, Sylvester N, Sarica O, Shoham O, Brill J (1994) A comprehensive mechanistic model for upward two-phase flow in wellbores. SPE Production \& Facilities SPE.

19. Hasan A, Kabir C (2005) A simple model for annular two-phase flow in wellbores. SPE Production and Operations.

20. Chen N (1979) An explicit equation for friction factor in pipe. Ind Eng Chem Fundamentals 18: 296-297.

21. Schubring D, Ashwood A, Shedd T, Hurlburt E (2010a) Planar laser-induced fluorescence (PLIF) measurements of liquid film thickness in annular flow. Part I: Methods and Data. Int J Multiph Flow.

22. Schubring D, Shedd T, Hurlburt E (2010c) Studying disturbance waves in vertical annular flow with high-speed video. Int J Multiph Flow.

23. Schubring D, Shedd T, Ashwood A, Hurlburt E (2010b) Planar laser-induced fluorescence (PLIF) measurements of liquid film thickness in annular flow. Part II: Analysis and comparison to models. International Journal of Multiphase Flow.

24. Bai X, Newell T (2002) Investgation of two-phase viscous liquid flow. International Refrigeration and Air Conditioning Conference. Lafayette, Indiana: Paper 590.

25. Alamu M, Azzopardi B (2011) Simultaneous investigation of entrained liquid fraction, liquid film thickness and pressure drop in vertical annular flow. J Energ Resour Tech.

26. Paz R, Shoham O (1999) Film-thickness distribution for annular flow in directional wells: Horizontal to vertical. Society of Petroleum Engineers.

27. Butterworth D (1972) Air-water annular flow in a horizontal tube. Progress in Heat and Mass Transfer. 